\title{
Dual practice and inequities in access to healthcare: A qualitative study from Kandy
}

Ramya Kumar ${ }^{1}$

${ }^{1}$ Department of Community and Family Medicine, Faculty of Medicine, Jaffna

\begin{abstract}
Sri Lanka's public and private health sectors are intimately connected by doctors who divide their work time between public and private. Such dual practice has allowed the government to maintain a strong public sector physician workforce at relatively low levels of health spending, but its implications for access are understudied. This paper examines the nuts and bolts of doctors' dual practice from the perspective of users. While showcasing inequities in access, the findings call for intervention by the relevant regulatory bodies and medical associations to uphold the ethical and professional standards of medical practice in Sri Lanka.
\end{abstract}

\section{Background}

Sri Lanka's health system comprises public and private health sectors, which have run in parallel since colonial times. The British colonial government encouraged public sector specialists to engage in private practice to maintain low wages in the public sector. Crucially, this form of dual practice created a channel through which private sector patients gained direct entry to government hospitals. Evaluation of the health sector in 1950 attributed overcrowding in state hospitals to dual practice. $^{1}$

In the late $1950 \mathrm{~s}$, the independent government began to restrict private practice privileges, first by banning dual practice for newly qualifying public sector specialists and medical officers. While the ban did not see strict implementation, strike action by the Government Medical Officers' Association resulted in the government removing the ban in the early 1960s, after which public sector specialists could engage in dual practice at designated state administered 'channelling centres.' These centres generated revenue for the government by retaining a portion of the consultation fee. ${ }^{2}$
In 1970, the government tried to phase out dual practice by prohibiting public sector specialists from engaging in private practice in stations where non-state specialists were available full-time in the private sector. This piece of legislation resulted in many public sector specialists retiring from state service to work full-time in the private sector. In 1977, the incoming government removed the ban, extending dual practice privileges to medical officers and other health professionals. ${ }^{2}$ Today dual practice is widespread in Sri Lanka with the majority of private medical practitioners being state employees. ${ }^{3}$

The legislation of dual practice is known to contribute toward retaining physicians for public systems of Low Middle Income Countries (LMICs). Even so, dual practice has given rise to high levels of absenteeism and a range of unethical practices, largely neglected by regulatory authorities, in various settings. ${ }^{4,5}$ Although associated malpractice is reported in the media, ${ }^{6,7}$ dual practice remains an understudied phenomenon in Sri Lanka.

This paper delves into dual practice from the perspective of healthcare users drawing on data from a larger critical qualitative study ${ }^{8}$ that explored how the presence of private healthcare shapes access in Kandy. The project received approval from the Research Ethics Board of the University of Toronto.

\section{Methodology}

This research was carried out in the Udawatta Grama Niladhari Division (name changed to protect anonymity of participants) in the Kandy Four Gravets Division, $<4$ km from Kandy City. Udawatta is situated in close proximity to several public and private healthcare facilities. Within the division is a public maternal and child health clinic, two public Ayurveda dispensaries, and several private general practitioner (GP) clinics. A Primary Medical Care Unit offers walk-in 
services about $1 \mathrm{~km}$ away. Four public tertiary care centres - including a dental hospital and a facility for children - are located within a $3 \mathrm{~km}$ radius. In addition, a number of GP clinics, channelling centres, diagnostics centres, pharmacies, and a private hospital are clustered $<1 \mathrm{~km}$ from the Division.

Women $>18$ years with at least two years of residence in Udawatta were eligible to participate in the study. Purposive recruitment took place in five study areas, stratified by social class and ethnicity (Table 1), until a sufficiently wide spectrum of social locations and healthcare experiences were covered, and similar themes repeatedly emerged in discussions and interviews.

Data were gathered by a questionnaire, 5 focus group discussions (FGD) and 22 individual interviews. The FGDs (one in each study area) were conducted at two community centres, with participation ranging from 4 to 8 women per FGD. Except in Study Area 5, where the FGD was conducted in English, all others were carried out in Sinhala. The duration of FGDs ranged from about an hour to an hour and 45 minutes. Twenty-three women participated in the interviews. Of them, 13 also participated in a FGD. All but one interview took place in the women's homes; the other, in an office. Two women - patient and caregiverparticipated in one of the interviews, explaining the discrepancy in the number of interviews and participants. Sixteen were carried out in Sinhala, and the rest (6) in English. Interviews lasted from 55 minutes to 2 hours and 20 minutes.

Audio-recorded FGDs and individual interviews were transcribed. Each case was summarized-bringing together field notes, transcripts, and survey data--to perform cross-case analysis. A theoretical reading of the data was guided by sensitizing concepts drawn from theoretical assumptions, the literature, and the researcher's experiences. In vivo concepts were identified during this reading. Data were coded using HyperRESEARCH (v3.7.3) and a thematic analysis was performed in relation to the study objectives.

\section{Findings and discussion}

As will be seen, healthcare users took advantage of dual practice, with perceived benefits varying by social class and ethnicity. Poor women used dual practice to access standard elements of care, such as timely services and one-to-one time with their public sector specialists in the private sector. In contrast, better-off users exploited dual practice to shortcut access to resource-intensive technologies and enjoy numerous privileges at public hospitals, even as they reduced out-of-pocket expenses in the private sector. In what follows, the numbers and letters following pseudonyms signal the study area and reported ethnicity of the quoted participants. See Table 1 for numbers; letters denote: ' $S$ ' Sinhala; 'Ma' - Malay; 'Mu' - Muslim/Moor; and ' $\mathrm{T}$ ' - Sri Lankan Tamil. 'They' is used when the gender of the healthcare provider was not specified by the participant.

\section{Paying for private attention}

The out-patient departments (OPD) of Kandy's public tertiary care centres were congested, with lengthy wait-times, brief consultations, and minimal continuity of care as doctors worked on a rotational basis. Feroza (2/Mu), a homemaker, had initially visited the OPD with painful joints, but later opted for private care: "[The OPD doctor] did not even check me, I was in so much pain but they

Table 1 . Study areas by social class and ethnicity

\begin{tabular}{|c|l|l|c|}
\hline Study area and language & \multicolumn{1}{|c|}{ Social class } & \multicolumn{1}{|c|}{ Ethnicity } & No. \\
\hline 1 - Sinhala & Working class & Malay, Muslim, Sinhala & 11 \\
\hline 2 - Sinhala & Lower-middle class & Muslim & 4 \\
\hline 3 - Sinhala & Lower-middle class & Sinhala, Muslim & 6 \\
\hline 4 - Sinhala & Middle/upper-middle class & Sinhala & 9 \\
\hline 5 - English & Upper-middle class & $\begin{array}{l}\text { Sinhala, Sri Lankan Tamil, } \\
\text { Mixed }\end{array}$ & 10 \\
\hline Total sample & & & 40 \\
\hline
\end{tabular}


did not listen to me. [They] gave me paracetamol and Brufen (ibuprofen) and asked me to leave." The out-patient clinics served thousands of people on a daily basis. Pushpa (3/S), who had recently survived a heart attack, spent the entire day at the hospital, seeing the doctor very briefly before standing in line again to refill her prescription: "Even if [we] go at 6 in the morning, [we] don't get the medicines till 1 or 2 (pm)."

These concerns translated to widespread dissatisfaction with OPD and clinic services, with many, except residents of the most disadvantaged study area (1), visiting a private GP or specialist. Yet, poorer women could not afford to address all their healthcare needs in the private sector, often consulting a public sector doctor in the private sector, while obtaining medicines and other procedures at a public facility. Amali (3/S), who ran a snack bar and was always busy, consulted a private GP who practiced close by, as she did not have time to waste at the OPD. When anything beyond a consultation and basic treatment were required, her GP-who was also a medical officer at the Peradeniya Hospital -arranged for these services at his hospital. Similarly, Indrani (3/S) visited the Kandy Hospital's Cardiology Clinic for her monthly prescription, while channelling her public sector cardiologist every three months to ensure she received his undivided attention. At the Cardiology Clinic, a junior doctor would order her prescription based on the specialist's instructions documented in her private medical records: "[They] don't change Sir's (the specialist's) prescription so I get the medicines from the [public] hospital."

In this way, many economically disadvantaged women like Indrani tried to better the quality of care they received by channelling a specialist in the private sector. Yet, many who visited channelling centres faced disappointment. Dilrukshi's (3/S) niece, in the early stages of pregnancy, saw her public sector specialist at the Amaya Medical Centre every month to obtain the specialist's attention throughout her pregnancy. Dilrukshi usually accompanied her niece--who traveled to Kandy from out-of-town-on visits to the specialist. At their most recent consultation, they had paid the channelling fee and waited several hours. When they finally met the specialist, their consultation was brief:
"We didn't get a chance to speak with [the doctor]... [At her last visit the doctor] asked [my niece] to bring a blood report ... something was low in her blood, something or the other. So I asked [the doctor] about this. "No, that's no problem, it will be okay if you take this medicine," that's all [the doctor] said. And we came out [of the room] ... not even five minutes...."

Even the poorest residents of Study Area 1 channelled when they had difficulty accessing the public system. When Shereen (1/Ma), a young woman with a disability, initially began to trip and fall-early signs of a debilitating neuromuscular condition-she visited the Kandy Hospital's OPD, but was repeatedly turned away by doctors who did not recognize her problem: "[I] knew my problem was getting worse because I was tripping up and falling more and more." So, Shereen channelled a neurologist who worked at the Kandy Hospital. When she explained that she could not afford private care, the specialist provided a referral letter that enabled direct entry to the specialist's public sector unit.

Similarly, Siththy (1/Ma), a homemaker, accompanied her daughter to the Amaya Medical Centre for a channelled consultation because the doctors at the Peradeniya Hospital's Medical Unit--where her daughter had been admitted days earlier-did not diagnose her daughter's psychiatric condition. Paying no heed to Siththy, the doctors at Peradeniya Hospital had investigated her daughter for a kidney problem, and subsequently discharged her with a clean bill of health. At the channelling centre, Siththy did not know whom to channel, and, on the advice of the "girl" at the reception, channelled a specialist who ordered a battery of tests and asked her to return for a second consultation. As Siththy could afford neither the tests nor consultation, she did not bring her daughter for a second visit. In this instance, Siththy paid the channelling fee, which she could barely afford, to no avail, and returned to Peradeniya Hospital.

The above suggests that dual practice allowed poorer women of Udawatta to easily access specialist attention in the private sector. By doing so, some users improved the quality of care they experienced, while others did not. As will be seen, users who felt marginalized by the public system- 
-represented by Muslim women in this study-took advantage of dual practice for very different reasons.

\section{Paying for respectful public services}

Unlike their Sinhala counterparts, lower-middle class Muslim women-represented by Study Area 2-routinely channelled the relevant public sector specialist in the private sector before entering a public facility. Channelling was perceived to confer protection from the discriminatory attitudes of ward staff. As Sabina (2/Mu), who wore a hijab, ${ }^{1}$ explained, public sector healthcare workers showed prejudice toward such markers of ethnicity: "I don't know why, [the shawl] is such a big issue, as soon as [the staff] see someone in a shawl, it's as if [they] get possessed." When Sabina visited her friend, who wore niqab ${ }^{2}$ after her delivery at the Kandy Hospital, she recalled how a nurse had scolded her friend at the maternity unit: "“Remove [it]!" [the nurse] said, "Everyone has to [dress] the same here... what are you doing... wearing that thing and fooling around." "Feroza (2/Mu) felt more confident about entering the public system with a private connection: "When [you] channel, the doctor will give a date ... then [you] can go to the government hospital because [the doctor] will attend [to your needs]."

Sabina (2/Mu) emphasized that such 'connections' had been crucial to accessing timely care during her pregnancies: "If we have the doctor's seal from the private sector, [they say,] "Ah this is that doctor's patient, send her quickly [to the labour room]. "She recalled an experience with a midwife at the Kandy Hospital's maternity unit when she informed her that her baby was inactive: "She told me, "Once every hour if the baby moves is enough, you wait without complaining and mind your business.", ", The next morning, the specialist had stopped by Sabina's bedside, recognizing her from his private practice. When he patted her arm to reassure her, he discovered she was running a temperature: "The doctor yelled at the nurses to bring a thermometer - to see my temperature was over 100!" Sabina had an emergency caesarean section, and her baby 1 "A head covering worn in public by some Muslim women."9

2 "A veil worn by some Muslim women in public, covering all of the face apart from the eyes."

Vol.30, No.1, July 2018 remained in the "baby room" for 11 days. Had she not channelled, Sabina was convinced, the day would have ended in disaster: "Only because the doctor came and saw me, God was there, I thought about what a narrow escape both my baby and I had [that day]."

Despite a preference for private care, economic concerns compelled these women to transfer into the public system for inpatient care. Sabina (2/ $\mathrm{Mu})$ channelled throughout her three pregnancies, but had delivered at public hospitals. Feroza's $(2 / \mathrm{Mu})$ mother accessed private outpatient care for chronic constipation, but got admitted to the Peradeniya Hospital when her condition worsened. And Fathima $(2 / \mathrm{Mu})$ had channelled private sector specialists for her arthritis for decades, but eventually turned to the public system for knee replacement owing to steep private sector charges.

Thus, Muslim women grappled with their marginality within the public system by establishing private 'connections' before accessing public healthcare. They were doubly disadvantaged as they confronted discrimination in the public sector and paid to protect themselves from prejudiced public healthcare workers. As will be seen, wealthier middle to upper-middle class residents exploited dual practice to receive a series of advantages that were inaccessible to their poorer neighbours.

\section{Short-cutting access to public services}

Better-off users - represented by residents of study areas 4 and 5-routinely accessed the private sector for outpatient care. However, these women often entered the public system through a private specialist for resource-intensive care, citing various reasons, including quicker service, unavailability of private options, and the unaffordability of private healthcare.

Facilitated by dual practice, some women reported having bypassed lengthy wait-times for overstretched public services. Anoja (4/S), a retired clerk, felt that channelling expedited care for her husband. Their private specialist admitted her husband to his medical unit at the Peradeniya Hospital for an urgent CT scan to investigate memory loss. Anoja believed diagnosis of his brain tumour would have been delayed had they accessed the OPD instead. Similarly, Mala (5/S) circumvented the queue for echocardiography at 
the Kandy Hospital by channelling her cardiologist at the Kandy Channelling Centre: "I went to do my stress test twice and for ECHO." She would bring the referral letter provided by her cardiologist to the Kandy Hospital's Cardiology Unit where the nursing staff would direct her to the cardiologist who would attend to her needs on a priority basis.

At times, dual practice enabled access to public services, not available in the private sector. Sakuntala $(5 / \mathrm{T})$, the spouse of a retired professor at the University of Peradeniya, received prompt attention at the Kandy Hospital's Ophthalmology Unit because the specialist, whom she also consulted privately, was a past student of a doctor relative: "I don't even sit and wait [at the clinic]... There's like 100s [of people there]. [He] says come at 9 o'clock, I go at 9 o'clock... [The nurse] will put me in the doctor's room and check the eye pressure and I'm out in 10 minutes flat. "Sakuntala attended the public sector clinic because the Amaya Medical Centre, where she channelled the specialist, did not have the equipment for monitoring glaucoma. Through the same specialist, her professor husband entered the Ophthalmology Unit for cataract surgery where he received "VIP" treatment: "There is a VIP room or something, it's like a large hotel room, large, bigger than our bedrooms... with attached bathroom, A/C (air 115 conditioning)... nobody can pay and get it, the doctor has the freedom to put you in that room." As Sakuntala pointed out, these VIP services were not available to less privileged users.

In fact, the primary reason Mala $(5 / \mathrm{S})$ channelled her cardiologist was to ensure timely access to the Kandy Hospital's Cardiology Unit, known to offer the most advanced cardiac care available in Kandy. As angiography was not (as yet) available in the private sector in Kandy, private healthcare users travelled to Colombo to access the procedure at a private hospital. The alternative for less well-off patients was to wait their turn at the Kandy Hospital, which often involved a six-month waiting period. However, according to Indrani (3/S), cardiologists at the Kandy Hospital had devised a more expedient alternative--a 'private list' at the Kandy Hospital for private patients who could afford to purchase the necessary consumables in the private sector:

"[When I went to the operating theatre] I saw [private patients] carrying all these $-10-$ gadgets and waiting, dressed for the theater. I asked a gent waiting there what those things were and he said they were for an angiogram... he had been given a date in the private sector by the 'Sir'(specialist) who did my angiogram."

Like the group she encountered at the angiography unit, Indrani too had fast-tracked access to angiography, although by different means. When Indrani $(3 / \mathrm{S})$ 's professor friend heard the news about Indrani's chest pain, she called up a cardiologist, and arranged for Indrani to undergo urgent angiography:

\section{"I went to the [Kandy] Channelling Centre the next day and saw [the cardiologist]. [She] gave me a letter, and told me that she would take me soon for the angiogram. "I want to do this for you quickly because "madam" (the professor) asked me," she said. So I got the chance to do [the angiogram] quickly."}

In some instances, dual practice also allowed privileged users to improve qualitative aspects of public care. As Muditha (4/S), whose husband was recently to the Peradeniya Hospital, remarked: "When [the nurses] realise we are the doctor's [private] patient, we get a bed and special attention." This was critical in the overcrowded public hospital setting where beds were hard to come by. As was observed by Muslim residents of Study Area 2, gaining admission via channelling also translated to courteous treatment. When Muditha visited her husband at the Peradeniya Hospital, she observed that healthcare workers were more attentive and respectful to private patients: "[I] feel they are more compassionate, [they] don'tyell at us...." In addition, many among this privileged group cited economic reasons for using dual practice.

\section{Reducing out-of-pocket expenses}

Many better-off Udawatta residents transferred to the public sector when out-of-pocket expenses were difficult to bear. When Anoja (4/S), a retired clerk, felt her husband's insulin was a burden on the home economy, she asked her husband's private sector specialist to refer them to his public clinic at the Peradeniya Hospital: "I told the doctor [the cost was too much for us]. " Thereafter, Anoja's 
husband consulted his specialist in the private sector, while obtaining insulin and other medicines free-of-charge from the specialist's medical clinic.

Such economic concerns were more pressing when inpatient care was required. As Muditha (4/S), a self-employed seamstress, remarked: "If [we] need to be admitted for a long time, we can't stay at a private hospital no... there will be big charges. "When Muditha's husband first developed symptoms of cirrhosis, they went directly to the OPD at Peradeniya Hospital on the advice of their private family doctor. Instead of attending the specialist's public sector clinic for follow-up, they channelled the same specialist at (private) Suwasevana Hospital. When her husband needed albumin transfusion, they re-entered the public system through the specialist: "The doctor told us that if [we] go private, [one albumin bottle] would cost 3500 . We thought this would be a waste." During her husband's hospital stay, out-of-pocket expenses had been minimal: "If [we] went private, it would have been wasteful spending no.... they even charge for cotton wool at Suwasevana."

For similar reasons, Nalini $(5 / \mathrm{S})$, retired from the hospitality industry, turned to the public system for womb surgery. Nalini asked the gynaecologist she consulted at Suwasevana Hospital to transfer her to his public sector unit for surgery: "Of course I was little stingy... when doctor said 45,000 [for the operation] I thought, oh god, I can buy two saris. " With a referral letter from the gynaecologist, she went to his clinic at Peradeniya Hospital where she received an early date for surgery.

Meanwhile, poorer women felt the consequences of this 'double dipping,' enabled by dual practice. Damayanthi (1/S), a retired janitor without 'connections,' was delayed many times at public clinics: "Even if we go veryearly in the morning [to the clinic], the patients who channel get preference. These patients arrive late and get what they need and leave quickly." Nafeesa (1/Mu), a homemaker whose spouse was a daily waged worker, was held up several hours as she waited for an ultrasound scan at the Kandy Hospital's Radiology Unit: "There were [private] patients with letters from the [specialist]. Those [scans] were done quickly and [they] were sent off." In other words, dual practice allowed privileged women to bypass wait-lists at public facilities and reduce out-of-pocket expenses on healthcare, while socially and economically disadvantaged women stood around for hours waiting their turn.

\section{Conclusion}

Dual practice enables healthcare users to see the same doctor in public and private sectors. While doing so presents advantages to some users, access to such benefits differ markedly by social location. On one hand, socially and economically disadvantaged women exploit dual practice to ensure they receive a very basic standard of care. On the other, doing so, enables better-off users to shortcut access to the public system, enjoy various privileges and economize on healthcare.

These inequities in access are compounded by the fact that the public healthcare system is financed largely through indirect taxation where a greater contribution comes from poorer healthcare users. Even so, it has been argued that the Sri Lankan health system is pro-poor because the wealthy opt out of public healthcare. ${ }^{10}$ However, the present study calls this assertion into question by demonstrating that better-off users do, in fact, access the public system, particularly for resourceintensive care.

Even as the state permits dual practice to save on health expenditure on physician salaries, such practice presents a lucrative supplementary source of income for public sector medical professionals. User experiences in Kandy suggest that dual practice, in its present unregulated form, may be riddled with conflicts of interest, exacerbated by weak mechanisms of accountability, ${ }^{11}$ in both public and private health sectors, making users vulnerable to exploitation. While showcasing inequities in access, these findings call for intervention by the relevant regulatory bodies and medical associations to uphold the ethical and professional standards of medical practice in Sri Lanka.

\section{References}

1. Jones M. The hospital system and health care: Sri Lanka, 1815-1960. New Delhi, India: Orient BlackSwan; 2009.

2. Jayasuriya, Lucian. Help with research [Internet]. Message to Ramya Kumar. 2017 Jul 25.

3. Govindaraj R, Navaratne K, Cavagnero E, Seshadri SR. Health care in Sri Lanka: what 
can the private health sector offer? [Internet]. Washington D.C: World Bank; 2014. Available from: https://openknowledge.worldbank.org/bitstream/ handle/10986/20018/899540WP0Box380th0Car eOinOSriOLanka.pdf

4. Hipgrave DB, Hort K. Dual practice by doctors working in South and East Asia: a review of its origins, scope, impact and the options for regulation. Health Policy Plan. 2014;29(6):703-716.

5. McPake B, Russo G, Hipgrave D, Hort K, Campbell J. Implications of dual practice for universal health coverage. Bull World Health Organ. 2016; 94:142146.

6. De Silva I. Ven. Sobitha's untimely death. The Island. 2015 Nov 15.

7. Perera K. Doctors were accepted as noble practitioners. EyeSriLanka [Internet]. 2017 Mar 26. Available from: http://www.eyesrilanka. com/2017/03/26/doctors-were-accepted-as-noblepractitioners/
8. Kumar R. The privatization imperative: women negotiating healthcare in Kandy, Sri Lanka. PhD dissertation [internet]. University of Toronto; 2018. Available from: https://tspace.library.utoronto.ca/ bitstream/1807/82972/3/Kumar_Ramya_201803 PhD_thesis.pdf

9. Oxford University Press. English Oxford Living Dictionaries [Internet]; 2018. Available from: https:// en.oxforddictionaries.com/

10. Rannan-Eliya RP, Sikurajapathy L. Sri Lanka: "good practice" in expanding health care coverage [Internet]; 2009. Available from: http://www.ihp.lk/ publications/docs/RSS0903.pdf

11. Rupasinghe P. Medical negligence and doctor's liability; a critical review in present legal regime in Sri Lanka [internet]. Ratmalana, Sri Lanka: Kotelawala Defence University; 2015. Available from: http:// www.kdu.ac.lk/proceedings/irc2015/2015/law-043. pdf 